\title{
Achieving Resilience through Knowledge Management Practices and Risk Management Culture in Agri-food Supply Chains
}

\begin{abstract}
Authors:
Imran Ali, Lecturer, School of Business and Law, Central Queensland University, Australia (e-mail: $\underline{\text { i.ali@cqu.edu.au })}$

Ismail Golgeci*, Associate Professor, Department of Business Development and Technology, Aarhus University, Denmark (e-mail: i.golgeci@btech.au.dk)
\end{abstract}

\begin{abstract}
Ahmad Arslan, Professor, Department of Marketing, Management \& International Business, Oulu Business School, Oulu Business School, University of Oulu, Finland. (email: ahmad.arslan@oulu.fi)
\end{abstract}

* Corresponding Author

This is an author accepted manuscript (AAM) version of the paper published in "Supply Chain Management" (Emerald).

Kindly cite the paper as follows:

Ali, I., Golgeci, I., \& Arslan, A. (2021). “Achieving Resilience through Knowledge Management Practices and Risk Management Culture in Agri-food Supply Chains", Supply Chain Management. Emerald. Available online at https://doi.org/10.1108/SCM-02-2021$\underline{0059}$ 


\title{
Achieving Resilience through Knowledge Management Practices and Risk Management Culture in Agri-food Supply Chains
}

\begin{abstract}
Purpose - Given the increasingly turbulent business landscape and unprecedented incidents (e.g., Covid-19), firms must achieve supply chain resilience as a dynamic capability to bounce back from adversities and ensure continuity of operations. This study integrates the three interrelated (knowledge management, risk management culture, and resilience) but often separately discussed concepts to advance the understanding of their intertwined influence on supply chain resilience in the agri-food supply chains.
\end{abstract}

Design/methodology/approach - The study employs a cross-sectional survey approach where quantitative data is collected from 349 participants from the Australian agri-food supply chains to test the proposed hypotheses.

Findings - Exposure to supply chain risks triggers the deployment of specific knowledge management practices in the agri-food supply chains. Further, the analysis on serial mediation suggests that firms' knowledge management practices work sequentially (knowledge acquisition, assimilation, application) and develop a risk management culture to achieve supply chain resilience amid supply chain risks.

Practical implications - The findings inform practitioners and policymakers who seek to understand the key mechanisms that facilitate the development of supply chain resilience when facing supply chain risks, particularly in the Australian agri-food supply chains.

Social implications - The growth of the food industry through more resilient food supply chains could ensure sustained food supply and more employment opportunities.

Originality/value - Using dynamic capability theory, we devise a novel empirical model that explicates how knowledge management practices and risk management culture instigate the dynamic capability of supply chain resilience amidst supply chain risks facing agri-food supply chains.

Keywords Supply chain resilience; Knowledge management; Risk management culture;

Agri-food supply chains; Empirical.

Paper type Research paper 


\section{Introduction}

Today's extended and complex supply chains operate in riskier business environments than ever before. The increased length and complexity of modern supply chains has exposed them to inevitable disruptions often elicited by a low level of visibility, demand volatility, production breakdown, and supply failures. Given that supply chain risk is an inevitable reality of a dynamic business landscape, supply chain resilience (SCRes) has been widely suggested as an instrumental capability to prevent, absorb, resist, and quickly recover from disruptions and ensure the intactness and continuity of operations in the agri-food supply chains (Ponomarov and Holcomb, 2009; Ali et al., 2018).

The research on supply chain risk and resilience has seen steep growth over the past two decades. Prior studies suggest a range of benefits and strategies for building SCRes (Ali and Gölgeci, 2019; Kumar et al., 2018; Wagner and Bode, 2008). Likewise, an array of prior studies offer insights into sources or antecedents of supply chain risks (Ho et al., 2015; Chaudhuri et al., 2020; Rao and Goldsby, 2009; Jüttner et al., 2003), risk-performance nexus (Ali et al., 2018), or risk management strategies (Christopher et al., 2011; Li et al., 2006; Talluri et al., 2013; Manuj and Mentzer, 2008b; Tse et al., 2019). Some studies on supply chain risk management (SCRM) conceive that exposure to supply chain risks, which represents the experience of risks and assessment/knowledge of potentially negative impact/loss, could work as a stimulus towards risk mitigation or resilience initiatives (Zsidisin et al., 2005b; Handfield et al., 2020). However, survey-based empirical research investigating the underlying mechanisms that lead to the development of resilience amid exposure to supply chain risks is still incipient, specifically in the context of agri-food supply chains.

In recent years, some scholars espoused the significance of knowledge management practices (Zsidisin et al., 2005a), such as knowledge acquisition, assimilation, and application (Ambulkar et al., 2016; Rodriguez and Edwards, 2009; Massingham, 2010), and risk 
management culture (RMC) (Liu et al., 2018; Christopher and Peck, 2004) in response to supply chain risks. Knowledge acquisition, for instance, allows firms to acquire new knowledge required to deal with distinctive challenges (Hult et al., 2007). Knowledge assimilation involves processing newly acquired knowledge in a form that employees can easily understand and absorb. Being a final step, knowledge application facilitates knowledge utilization to mitigate the threats. Likewise, RMC develops daily routines and behaviors to identify and mitigate different risks through active engagement and teamwork (Liu et al., 2018). Despite some early conceptualizations, however, it is unclear whether and how such capabilities could facilitate the development of SCRes amidst exposure to supply chain risks. In particular, the role of specific knowledge management practices of knowledge acquisition, assimilation, and application in SCRes received scant attention. Even less attention has been paid to identifying potential mediating mechanisms linking knowledge management practices and RMC to pursue SCRes in agri-food supply chains.

With this study, we aim to demonstrate the key mechanisms of knowledge management practices and $\mathrm{RMC}$ that are triggered in response to supply chain risks and thereby lead to SCRes in agri-food supply chains. The agri-food industry is a significant contributor to the economy, employability, and food supply in Australia and many countries worldwide (Ali and Govindan, 2021). For instance, the industry substantially contributes to the gross domestic product of many developed and developing economies of the world, for example, the USA (5.2\%) (USDA, 2021), New Zealand (5.7\%), Brazil (5.9\%), Australia (1.9\%), China (17.8\%), India (18.3\%) Indonesia (13.7\%), Turkey (6.6\%) and Pakistan (22.7\%), among many others (World Bank, 2021). However, this industry is subject to unique operational challenges such as seasonal production system but pressure for constant food supply round the year, extreme exposure to natural weather conditions, long lead time, fast-changing consumers' preferences, high supply-demand variations (Ali and Gölgeci, 2020; Leat and Revoredo-Giha, 2013). 
Contemporary agri-food supply chains are globally interconnected, and therefore, a disruption at any stage could cause a shortage of food supply and severe economic losses in several regions. To investigate the potential detrimental factors and reliable measures to build more resilient food supply chains, we use the Australian agri-food supply chains, which are wellknown for producing and supplying premium quality agri-foods worldwide (Ali et al., 2017).

Grounded in dynamic capability theory (DCT), our research study is an early effort to examine the nexus between exposure to supply chain risks, RMC, and SCRes undertaking the Australian agri-food supply chains. We empirically demonstrate that SCRes is developed when exposure to supply chain risks triggers knowledge management practices and RMC in firms within these supply chains. Our study positions RMC as a potential linking pin between firms' knowledge management practices and their SCRes in the Australian agri-food supply chains. Since supply chain risks are unavoidable, successful firms employ knowledge management practices (knowledge acquisition, assimilation, and application) and thereby achieve SCRes.

\section{Theoretical background and hypotheses}

\subsection{Supply chain risk management and supply chain resilience}

Supply chains are increasingly becoming more susceptible to volatile, uncertain, and risky business environments due to challenges stemming from the increased complexity, interconnectedness, and interdependence of global production (Golgeci et al., 2020; Tse et al., 2021). Accordingly, the research on SCRM has obtained an important status at the interface of supply chain management and risk management (Manuj and Mentzer, 2008a; Ambulkar et al., 2016; Revilla et al., 2017; Hult et al., 2010; Bakshi and Kleindorfer, 2007). SCRM is defined as "the identification of potential sources of risk and implementation of appropriate strategies through a coordinated approach among supply chain members, to reduce supply chain 
vulnerability" (Manuj and Mentzer, 2008a, p. 205). It is concerned with managing various risks involved in supply chains amid crisis, disruptions, and unexpected adversity.

Scholars have, thus far, paid extensive attention to classifying risks involved in supply chains (Wagner and Bode, 2006; Rao and Goldsby, 2009; Wang et al., 2017), as well as recommended measures and steps applied against various sources of supply chain risks (Manuj and Mentzer, 2008b; Manuj and Mentzer, 2008a). In terms of classifying supply chain risks, Rao and Goldsby (2009) proposed that environmental risks, industry risks, and organizational risks are among the primary sources of supply chain risks. Similarly, Wagner and Bode (2008) categorized supply chain risks into demand-side risks, supply-side risks, and catastrophic risks. A typical supply chain is composed of suppliers, focal firms, and customers. As such, a supply chain's performance can be mainly eroded by supply-side, production-related, or demand-side risks (Chen et al., 2013; Wagner and Bode, 2008; Kumar et al., 2019; Liu et al., 2018; Aitken et al., 2016; Mason-Jones and Towill, 1998). This study thus concentrates on supply risks (risks related to a firm's suppliers), production risks (risks associated with production processes and workforce), and demand risks (risks related to demand pattern and customer behavior) as major types of supply chain risks (Chen et al., 2013; Wagner and Bode, 2008; Kumar et al., 2019; Liu et al., 2018) (Zsidisin and Wagner, 2010) in the Australian agri-food supply chains.

Although sources of supply chain risks and SCRM strategies may vary across contexts and conditions, one of the important expected consequences of successful risk management is SCRes (Pettit et al., 2013; Brandon-Jones et al., 2014). Firms that invest in SCRes and are members of resilient supply chains in the wake of crises and disruptions are more likely to respond effectively to such crises and disruptions (Christopher and Peck, 2004; Golgeci and Ponomarov, 2013). SCRM is not the only way of understanding and explaining SCRes. Emergency management and sustainable development perspective could be another angle to understand the antecedents of SCRes. Nonetheless, SCRM is particularly relevant to SCRes 
when the focal subject matter is businesses rather than communities and societies (Ponomarov and Holcomb, 2009).

SCRes is defined as "the adaptive capability of the supply chain to prepare for unexpected events, respond to disruptions, and recover from them by maintaining continuity of operations at the desired level of connectedness and control over structure and function." (Ponomarov and Holcomb, 2009, p. 131). In this outlook, SCRes can be deemed a dynamic capability relevant to risks and disruptions. SCRM and ensuing SCRes are typically measured against the effectiveness of firm responses to realized supply chain risks of various types. That said, SCRes is especially imperative when potential disruptions cannot be anticipated, i.e., preventative measures cannot be employed (Sheffi and Rice, 2005). Accordingly, SCRM and SCRes go hand in hand, and not only pre but also post-management of supply chain risks could be an important source of SCRes.

\subsection{Dynamic capability view of supply chain resilience}

Dynamic capabilities are characterized as a “firm's ability to integrate, build, and reconfigure internal and external competencies to address rapid environmental changes" (Teece et al., 1997, p. 516). Dynamic capabilities allow firms to generate, deploy, and protect tangible/intangible assets and resources that contribute to sustained performance (Teece, 2007). They hinge on a firm's procedures that can systematically modify its capabilities and existing positions, leading to new positions and paths for making the best use of its strategic assets (Helfat and Peteraf, 2009). Adopting dynamic capabilities as its central concept, DCT has emerged as an important theoretical lens to explain the underlying features and behavioral micro-foundations of strategic management and value generation (Teece, 2014).

As DCT explains the nature and essence of long-term competitive advantage (Pitelis and Teece, 2010; Teece, 2014), SCRes can be positioned as a vital "dynamic capability" to withstand and bounce back from unexpected disruptions and survive in the long run (Gölgeci 
and Kuivalainen, 2020; Golgeci and Ponomarov, 2013). DCT acknowledges that dynamic capabilities may operate at the inter-organizational level of supply chain systems (Schilke et al., 2018). Furthermore, a recent systematic review of SCRes research reveals that DCT is among the most relevant theoretical lenses to explain the SCRes phenomena (Ali and Gölgeci, 2019). As such, SCRes can be theorized and analyzed as a relevant dynamic capability that can be leveraged in turbulent and unpredictable contexts against supply chain risks.

\subsection{Knowledge management and risk management culture}

In a world of growing complexity, constant change, and dynamism, knowledge is an indispensable source of competitive benefit for a firm (Grant, 1996; Yeniyurt et al., 2005). In fact, given the realities of the contemporary information age and considering the firm as a value-creating economic entity, the firm can be considered an organization for integrating and leveraging knowledge (Grant, 1996).

Knowledge management is described as "the process that creates or locates knowledge and manages the dissemination and use of knowledge within and between organizations" (Darroch, 2003, p. 41). Disseminating and sharing knowledge and contemporary business processes and the firm's capacity to absorb new technology and apply knowledge toward strategic ends are fundamental means of withstanding risk and uncertainty and staying competitive in the long run. Knowledge management may constitute different processes such as knowledge recognition, acquisition, assimilation, interpretation, sharing, transformation, application, and utilization that are pertinent to effective leverage of knowledge. Nonetheless, three more salient processes are knowledge acquisition, assimilation, and application (Jansen et al., 2005; Enkel et al., 2017; Xie et al., 2018; Zhang et al., 2015).

Knowledge acquisition constitutes “a firm's capability to identify and acquire externally generated knowledge critical to its operations" (Zahra and George, 2002, p. 189). Knowledge assimilation involves a firm's routines and procedures that enable it to analyze and 
understand information acquired from outside resources and integrate it with internal knowledge (Xie et al., 2018; Zhang et al., 2015). Knowledge application is defined as the procedures through which a firm exploits knowledge by integrating assimilated knowledge into its business processes to generate new knowledge and business-related outputs (Zhang et al., 2015). Overall, knowledge, particularly tacit inimitable knowledge that relies on socialbehavioral processes, comprises the primary source of competitive advantage (Grant, 1996).

Nevertheless, beyond being a critical source of positive outcomes, extant research argues that knowledge could also be leveraged as a hedge against risks, disruptions, and adversities (Zsidisin et al., 2005b; Rodriguez and Edwards, 2009; Hora and Klassen, 2013; Ambulkar et al., 2015). Many firms reinforce their knowledge management procedures and capabilities to weather, alleviate, and survive supply chain risks (Cantor et al., 2014). For example, Zsidisin et al. (2005a) and Zsidisin et al. (2005b) underline the significance of knowledge management through learning from the past disruptions, making changes in operations, and establishing guidelines to prevent future recurrence. Hora and Klassen (2013) view knowledge management as a means of learning from adversity and highlight the role of knowledge acquisition in alleviating operational risks. Hult et al. (2007) note that knowledge management routines could minimize lead time uncertainty. Cao et al. (2010) suggest that knowledge creation is an important precursor to supply chain collaboration, which could, in turn, help deal with risks from rapidly changing environments. Ambulkar et al. (2016) point out that a firm's capacity to mitigate supply chain risks depends on its employees' learning and knowledge management capabilities.

Going further, Teller and Kock (2013) assert that an important prerequisite for dealing with risk is developing, cultivating, and implementing RMC. RMC refers to a culture (norms and behavior) of acceptance and adoption of risk management principles and the embeddedness of risk management principles in the firm's decision-making processes (Christopher and Peck, 
2004). In firms with an established RMC, risks and risk management are principal considerations in the everyday aspects of firm decision-making (Roeschmann, 2014). RMC encompasses the overall awareness, assessment, and remediation of potential risks (Zsidisin et al., 2005b) and the possible benefits of their management/mitigation, embracing and being committed to risk management processes, and communicating and coordinating with relevant stakeholders (Teller and Kock, 2013). RMC reinforces the positive behaviors of employees to share concerns and instigate open discussion on how to manage risks as an intrinsic part of their day-to-day operations (Liu et al., 2018). Such a culture of open discussion and constant application of knowledge enormously supports firms to implement change at each level (Zsidisin et al., 2005a; Zsidisin et al., 2005b), thereby alleviating emergent threats (Rodriguez and Edwards, 2009). Accordingly, we present that knowledge management as a hook or linking pin between supply chain risks and RMC.

\subsection{Hypotheses}

\subsubsection{Direct effects}

One of the central axioms in management research is that firms' performance depends on the fit amongst a business and its external ecosystem (Donaldson, 2001; Hoffer, 1975; Drazin and Van De Ven, 1985). This line of logic, which has found solid ground in business and management research, infers that firms' behaviors are mostly triggered, and in some cases driven, by external forces. In today's complex and turbulent world, firms are constantly and insurmountably surrounded by risks and disruptions that are incalculable hazards to long-term performance and endurance (Colicchia and Strozzi, 2012). The sheer amount and frequency in which supply chain risks are realized, and the disruptions faced compel firms to adopt necessary measures to tackle such risks.

SCRM is a complex, knowledge-driven approach adopted in response to the stipulation to formulate and develop suitable performance measures to identify, assess, inform, and 
navigate the operational and strategic decisions against supply chain risks (Ritchie and Brindley, 2007). Supply chain risk exposure, which includes the experience of various risks and assessment of their potential negative impact/loss, is the essential step to reduce disruption (Zsidisin et al., 2004), or maintain resilience (Jüttner et al., 2003; Handfield et al., 2020). Risk identification tells what are the prevalent categories or sources of risks (Zsidisin et al., 2000), while risk assessment provides information (mostly based on historical data, experts' judgment, or experience of disruption) on how risk will impact the business performance ( Zsidisin, 2003). As such, risk assessment provides the critical link for knowledge acquisition concerning risk management and achieving supply chain resilience by identifying the risk sources that could not have otherwise been known.

Contemporary supply chains are extended and interdependent systems; therefore, risk exposure could involve all three sides of the supply chain - supply, production, and demand. (Kleindorfer and Saad, 2005; Christopher et al., 2011). Exposure to risks from different sides would trigger the firms to acquire new knowledge for suitable mitigation measures and effective resilience (Cantor et al., 2014; Ambulkar et al., 2016; Hora and Klassen, 2013; Zsidisin et al., 2005a). More specifically, when firms experience and understand the consequences of potential supply chain risks, they are stimulated to acquire new knowledge to reduce losses and maintain performance. For example, exposure to demand-side or supply-side risks would prompt supply chain partners' to acquire knowledge on better production planning along the supply chain (Hult et al., 2007). This would, in turn, provide firms with leverage against potential and realized supply chain risks, as well as a degree of certainty within uncertain external circumstances. Likewise, exposure to supply chain risks may also elicit knowledge assimilation processes, where the firm can better analyze, interpret, and understand potential mechanisms to mitigate them (Xie et al., 2018; Zhang et al., 2015). In particular, firms may transfer knowledge across firm functions during the knowledge assimilation 
processes to better grasp the nature of the risks being faced and prepare for an effective response to those risks. Furthermore, exposure to supply chain risks may stimulate firms to apply the acquired and assimilated knowledge to fend off those risks and establish risk mitigation mechanisms for current and future risks involved in supply chain operations (Cantor et al., 2014; Rodriguez and Edwards, 2009). Thus, we expect that firms' exposure to supply chain risks will trigger knowledge acquisition, assimilation, and application as major knowledge management components.

H1: A higher exposure to supply chain risks is positively associated with a firm's a) knowledge acquisition, b) knowledge assimilation, and c) knowledge application.

An important prerequisite for SCRM is developing, cultivating, and implementing firm RMC (Teller and Kock, 2013). RMC is defined as firm-wide acceptance and adoption of risk management principles and the embeddedness of risk management principles in the firm's decision-making processes (Christopher and Peck, 2004). It necessitates the awareness and knowledge of various risks, experience of disruptions, and reinvigoration of management/mitigation measures to prevent similar future incidents (Zsidisin et al., 2005a; Zsidisin et al., 2005b). In firms with an established RMC, risks and risk management are principal considerations in the everyday aspects of firm decision-making (Roeschmann, 2014). Nonetheless, RMC is beyond a mere mindset, and it is required to be nurtured via relevant business activities to take hold of the firm and realize its potential.

As the last main stage of knowledge management practices, knowledge application is especially pertinent to cultivating RMC, since RMC can involve alertness to external information and knowledge transfer between relevant parties. RMC augments firms' understanding of supply chain risks and fosters its capacity to identify critical variations in the supply chain (Liu et al., 2018). In this vein, knowledge application can serve as an essential underpinning force behind the adoption and manifestation of RMC by enabling the firm to 
become aware of its supply chain risks and alert to changes in its supply chain. For example, firms that apply knowledge effectively regarding suppliers' quality performance can foster RMC both within and across their boundaries. Likewise, knowledge application skills and activities are argued to be a vital contributor to a firm's risk mitigation competency that is tied to its RMC (Ambulkar et al., 2016). Accordingly, we expect that knowledge application within a firm can support its RMC.

H2: Knowledge application is positively associated with firm risk management culture.

While past research has examined various antecedents of SCRes (e.g., Pettit et al., 2013; Gölgeci and Kuivalainen, 2020; Golgeci and Ponomarov, 2013; Dubey et al., 2017; Scholten et al., 2014; Ponomarov, 2012; Brandon-Jones et al., 2014; López and Ishizaka, 2019), SCRM is often believed to be one of the key pillars of SCRes. Firms' strategic orientations and their organizational culture as a reflection of such strategic orientations profoundly affect their key capabilities and behaviors (Schweiger et al., 2019). For example, in a qualitative study on SMEs, Ates and Bititci (2011) posit that RMC drives the change process, which is a paramount capability to achieve resilience. In this vein, one can plausibly argue that RMC might be one of the most appropriate and relevant types of organizational culture that nurtures firms' SCRes (Liu et al., 2018; Kumar and Anbanandam, 2020; Jain et al., 2017).

Creating RMC within the firms can help key decision-makers decrease the supply chain risks for both the firm and its supply chain partners (Liu et al., 2018). It can also help firms grasp both the opportunities and threats in their context and react swiftly to the fluctuating external demands. Likewise, RMC can enable the firm to plan multiple contingencies to withstand supply chain disruptions and maintain SCRes in the face of adversities (Jain et al., 2017). Therefore, we expect that RMC is likely to play a positive role in SCRes.

H3: Risk management culture is positively associated with firm supply chain resilience.

\subsubsection{Mediation effects}


In H1, we explored the possible role of exposure to supply chain risk in a firm's knowledge acquisition, assimilation, and application. Although knowledge acquisition, assimilation, and application are distinct processes that constitute knowledge management as a holistic management approach, they are interconnected and follow a specific path in their deployment and manifestation (Zahra and George, 2002). In particular, while knowledge acquisition and knowledge assimilation represent the firm's potential absorptive capacity, knowledge application represents its realized absorptive capacity (Zahra and George, 2002). Accordingly, knowledge application is dependent on the extent and the success of preceding stages of knowledge acquisition and knowledge assimilation.

In the context of SCRM, firms that are keen on fostering their knowledge application in the pursuit of RMC and firm SCRes are often compelled to invest in their knowledge acquisition and knowledge assimilation. This is because exploiting knowledge to tackle disruptions and mitigate supply chain risks follows first identifying and acquiring externallygenerated new knowledge and then analyzing, interpreting, and incorporating the acquired knowledge into the firm's operations (Xie et al., 2018; Zhang et al., 2015). Without sufficient attention to and effective realization of external knowledge acquisition and ensuing knowledge assimilation, knowledge application is likely to be obstructed and tainted. Particularly, when SCRM is in question, external knowledge becomes vital, and firms may not be able to apply relevant knowledge without acquiring and assimilating them to overcome supply chain risks in the wake of adversity and disruptions. This line of evidence and argumentation indicates that knowledge acquisition and knowledge assimilation convey the role of supply chain risk in knowledge application. In other words, knowledge acquisition and knowledge assimilation convey may separately function as linking pins connecting supply chain risks and knowledge application. Thus, we propose the following two hypotheses on the expected mediating roles 
of knowledge acquisition and knowledge assimilation in the linkage between supply chain risk exposure and knowledge application

H4: Exposure to supply chain risk significantly affects a firm knowledge application through knowledge acquisition.

H5: Exposure to supply chain risk significantly affects a firm knowledge application through knowledge assimilation.

In addition to distinct mediating roles of knowledge acquisition and knowledge assimilation in the linkages between supply chain risk and knowledge application, we explore the possibility of serial mediation by investigating whether the influence of supply chain risk on knowledge application is mediated jointly and sequentially by knowledge acquisition and knowledge. This possibility goes above and beyond separate mediating roles of "knowledge acquisition and knowledge assimilation". Here, we further explore the path dependency between "knowledge acquisition and knowledge assimilation" in the firm's application of its knowledge.

Knowledge assimilation elicits analysis and interpretation of knowledge, which helps build a knowledge base of both employees and business partners (Kaufman et al., 2000). Subsequently, the knowledge application enables the utilization of knowledge to take decisive actions and solve business problems or neutralize prevalent business threats. Thus, supply chain risks entail knowledge-based competencies, including knowledge acquisition, assimilation, and application in a serial fashion.

Serial mediation is an approach to test the linkages between closely related and pathdependent constructs (Huertas-Valdivia et al., 2018; Do et al., 2018). As noted above, a similar case is evident between the concepts of knowledge acquisition, assimilation, and application. In the presence of high supply chain risks, a firm's knowledge assimilation may depend on knowledge acquisition to manifest its mediating role in responding to supply chain risks through knowledge management mechanisms. In light of past research on knowledge 
management, absorptive capacity, and SCRM, we believe that supply chain risks provoke knowledge acquisition, ultimately driving knowledge acquisition and subsequent knowledge application.

H6: Exposure to supply chain risk significantly affects a firm knowledge application through knowledge acquisition and knowledge assimilation together (one after another).

The conceptual model (Figure 1) presents the hypothesized relationships between SCRM, knowledge management practice, RMC, and SCRes.

\section{Insert Figure 1}

The proposed model theorizes that the presence of risks drives firms towards knowledge management practices, which, in turn, elicit risk management culture, ultimately leading to more resilient agri-food supply chains. In other words, the cultivation of SCRes would need a systematic and structured process of knowledge management and RMC in the wake of divergent supply chain risks.

\section{Methodology}

To collect the quantitative data, we used a survey method in which structured questionnaires, through Qualtrics software, were distributed among senior managers of the Australian agrifood supply chains. A "stratified random sampling technique" (Madow, 1953) was adopted to ensure that the population is evenly sampled.

\subsection{Measurement scales}

Our research framework includes eight constructs with multiple items. We have dug deeper into the relevant literature for understanding each construct and associated item. Drawing upon past research (Chen et al., 2013), supply chain risk was treated as a "higher-order (secondorder) construct" with three "first-order constructs": supply risks, production risks, and demand risks. The items (see Table 1) and constructs were borrowed from the prior studies, including 
“supply chain risk" (Chen et al., 2013; Wagner and Bode, 2008; Kumar et al., 2019; Liu et al., 2018), knowledge acquisition (Jansen et al., 2005; Xie et al., 2018; Zhang et al., 2015), knowledge assimilation (Jansen et al., 2005; Xie et al., 2018; Zhang et al., 2015), knowledge application (Jansen et al., 2005; Enkel et al., 2017; Xie et al., 2018; Zhang et al., 2015), RMC (Christopher and Peck, 2004; Liu et al., 2018; Sheffi and Rice, 2005) and SCRes (Dubey et al., 2019; Chowdhury and Quaddus, 2016). Each item was measured using 7-point Likert scales (Ali et al., 2018; Wagner and Bode, 2008), wherein 1 indicated "strongly disagree" and 7 represented "strongly agree". To ensure the reliability and validity of the questionnaire, we first run a pilot test using 68 respondents, including senior managers and academics (Churchill, 1979). These 68 respondents, who participated in the pilot test, were not used in the major survey.

\section{Insert Table I}

Following this, 1000 questionnaires were distributed among senior managers of the Australian agri-food supply chains. The involvement of senior managers ensures the credibility of responses. To increase the response rate, we sent three reminders by using the reminder options within Qualtrics. Overall, we received 349 valid responses, indicating a response rate of 34.9 percent.

\section{Findings}

\subsection{Demographic statistics}

The demographic information showed that 40 percent of participants belonged to small firms (<19 employees); whereas 60 percent belonged to medium-sized firms (20-199 employees). Further, 27 percent of the participants held the position of "owner-managers", 24 percent "general managers", 13 percent "operations managers", 11 percent "SC managers", 15 percent 
"directors", and 10 percent "managing directors". The data, thus, suggest heterogeneity in the target population.

\subsection{Common method bias, non-response bias, and endogeneity problem}

Since the survey questionnaire was completed by a "single informant", issues of "commonmethod bias" should be addressed. First, Harmon's single factor test was used where factor analysis extracted eight factors with eigenvalue 1.0. The "average variance extracted" by any individual construct or variable was found much smaller than the cutoff value of 50\% (Harman, 1976). Second, marker variable techniques (Williams et al., 2010; Craighead et al., 2011) were employed where no correlation between the marker variable and any other variable was found. Third, all observed variables were loaded to a "common latent factor (CLF)". A comparison between the standardized regression weight of the model with CLF" and "standardized regression weight of the model without CLF" suggested a non-significant $(p>0.05)$ difference. Hence, common method bias was not detected in our sample.

Non-response bias occurs when there is a significant variation in data across the early vs. late respondents of a survey. In this study, we compared the responses from early respondents (213) to the late respondents (136) using paired samples $t$-test, based on established guidelines of Armstrong and Overton (1977). The analysis suggested insignificant variance amid the early and late responses; thus, non-response bias was not detected in our sample. To further verify the existence or nonexistence of non-response bias, we also conducted Leven's Homogeneity of Variance Test (no variance across the sample), following the recent research in the field (Bag et al., 2020). The test confirmed that non-response bias was not an issue in our study.

Given the potential endogeneity issue, the explanatory factors possibly correlated with error terms due to unintentional elimination of a factor, and therefore the estimate of a model can be biased (Zhao et al., 2021). Thus, we took the necessary steps to address potential 
endogeneity bias following the guidelines established in the extant research (Sande and Ghosh, 2018).

\subsection{Measurement model evaluation}

In the measurement model, all latent variables were covaried using AMOS modeling Software version 26. The result suggested acceptable model fit indices (Hu and Bentler, 1999; Hair et al., 2010) including " $x^{2} / d f=1.349, \quad C F I=0.913, \quad G F I=0.923, \quad A G F I=0.812, \quad T L I=0.883$, $I F I=0.874, T L I=0.881, R M S E A=0.025, R M R=0.034, p=0.000 ”$. As Table I shows, factor loading for each item exceeds 0.50 (Hair et al., 2010), thus ensuring the item reliability. Further, values of both Cronbach's alpha $(\alpha)$ and composite reliability were much higher than the cutoff value of 0.70 (Nunnally, 1978; Hair et al., 2010), confirming construct reliability.

Convergent validity was ensured with "average variance extracted (AVE)" which exceeded the recommended value, i.e., 0.50 (Fornell and Larcker, 1981). The discriminant validity was confirmed by two means. First, the square root of AVE for each construct was greater than the correlation amongst the particular construct and other constructs (Table II) (Fornell and Larcker, 1981). Second, there was no issue of cross-loading items on other constructs (Hair et al., 2010). Further, the second-order model was separately tested where the second-order variable (supply chain risk) was regressed on three first-order variables (supply risks, production risks, and demand risks) to avoid the risk of potential error in our model. The result indicated good model fit indices (" $x^{2} / d f=2.131, C F I=0.891, G F I=0.92, T L I=0.918$, $I F I=0.894, \quad T L I=0.881, \quad A G F I=0.891, \quad R M S E A=0.025, \quad R M R=0.024, \quad p=0.000 ”), \quad$ thus confirming the presence of second-order construct in our model.

\subsection{Assessment of structural model}

To rigorously test the relationships in the proposed theoretical, we applied the "structural equation modeling (SEM) method with IBM SPSS Amos 26", which has the incredible ability to simultaneously test the complex relationships in the model. The goodness-of-model indices 
uncovered that our model fits good to the data (Hu and Bentler, 1999; Hair et al., 2010), including " $x^{2} / d f=1.325, \quad C F I=0.928, \quad G F I=0.937, \quad T L I=0.941, \quad A G F I=0.921, \quad I F I=0.923$, $T L I=0.942, R M S E A=0.015, R M R=0.024, p=0.000 ”$. Figure 2 and Table III show that the path coefficient from supply chain risk to knowledge acquisition is significant $(\beta=.19, p<0.05)$, corroborating Hla. The path coefficients from supply chain risks to knowledge assimilation and knowledge application are positive but non-significant $(\beta=.13 ; \beta=.14, p>0.05)$. Thus, $H 1 b$ and $H I c$ are not supported. The first controlled path coefficient from knowledge acquisition to knowledge assimilation is significant $(\beta=.21, p<0.05)$. By contrast, the second controlled path coefficient from knowledge acquisition to knowledge application is positive but insignificant $(\beta=.14, p>0.05)$. Further, the third controlled path coefficient from knowledge assimilation to knowledge application is significant $(\beta=.24, p<0.05)$. The path coefficient from knowledge application to RMC is positive and significant $(\beta=.31, p<0.01)$, corroborating $H 2$. Finally, the path coefficient from RMC to SCRes is highly significant $(\beta=.36, p<0.001)$, corroborating $H 3$.

Mediation effect. To test the mediation (indirect) effects, we performed bootstrap with 2000 bootstrap samples using SEM. Figure 2 and Table III present both direct and indirect (mediation) results. The direct link between supply chain risks and knowledge application is positive but insignificant $(\beta=.14, p>0.05)$. The indirect links between supply chain risks and knowledge application via knowledge acquisition as well as knowledge assimilation (separately) are positive but non-significant $(\beta=.12, \beta=.15, p>0.05)$. Thus, $H 4$ and $H 5$ were rejected. However, the indirect link between supply chain risk and knowledge application via knowledge acquisition and knowledge assimilation together (one after another) is positive and significant $(\beta=.28, p<0.01)$, thus confirming $H 6$. Thus, the findings unveil a positive outcome when exposure to supply chain risk drives knowledge management practices in sequential order of knowledge acquisition to knowledge assimilation to knowledge application. This also means 
that the process involving only knowledge acquisition or knowledge assimilation alone cannot significantly mediate the nexus between supply chain risks and knowledge application.

\section{Insert Figure 2}

\subsection{Control variables}

Considering that contextual variables may influence our results, this study controlled the influence of firm size, industry type, firm age, and managerial experience. The data included only SMEs from the agri-food sector, and hence no potential influence of firm size and industry type can be found on our results. Firm age and managerial experience were operationalised as a dichotomous variable with two groups: 5 to 10 years and greater than ten years. The analysis suggested non-significant $(p>0.05)$ variation among the groups. Thus, there is no risk of a significant influence of contextual variables on the main results of the model.

Insert Table II

Insert Table III

\section{Discussion and conclusions}

The scholarship on supply chain risk, knowledge management, RMC, and SCRes has been gaining growing interest from both industry managers and academics. Yet, most past studies have discussed these topics in isolation using conceptual, qualitative, or projection-based analytical models. As such, there is a scarcity of empirical studies at the intersection of these significant concepts particularly in the context of agri-food supply chains. This research bridges the current knowledge void in the past scholarship through an empirical model investing the nexus amongst supply chain risk, knowledge management, RMC, and SCRes undertaking the Australian agri-food supply chains. We contend that exposure to supply chain risks is an inevitable reality of a rapidly changing business environment and survival in such environments necessitates resilient supply chains. We then infer that SCRes is established when 
exposure to supply chain risks drive the firms toward knowledge management practices and RMC in agri-food supply chains.

\subsection{Research implications}

Our research offers several valuable theoretical contributions to the extant literature on agrifood supply chain management using the Australian agri-food sector. First, our research validates the relationships between three important and interrelated concepts, including supply chain risk, knowledge management, RMC, and SCRes in agri-food supply chains. The first part of the framework, which involves hypotheses $H 1 a-H 1 c$, demonstrates the mechanism on how exposure to supply chain risks persuade firms toward knowledge management practices, including knowledge acquisition, assimilation, and application in agri-food supply chains. Doing so, our research advance empirical insights into the current literature of agri-food supply chain, which is centered on the significance of risk management (Behzadi et al., 2017; Umar et al., 2017), performance measurement metrics (Moazzam et al., 2018; Juan Ding et al., 2014) or literature reviews (Siddh et al., 2017; Zhong et al., 2017; Barbosa, 2021).

Successful businesses develop new learning skills to remain competitive in turbulent business environments (Wang et al., 2007). Learning capabilities require knowledge management practices, whereas the changing business environment accompanies supply chain risks (Ali et al., 2018). Past research conceives a connection between supply chain and knowledge management (Rodriguez and Edwards, 2009; Cantor et al., 2014; Cao et al., 2010; Hora and Klassen, 2013; Ambulkar et al., 2015; Massingham, 2010), yet the literature lacks insights into whether and how supply chain risks drive the knowledge management processes, particularly in agri-food supply chains. Our paper advances prior research in this direction. We argue that supply chain risk is the dynamic and inevitable reality of a rapidly changing business environment triggering knowledge management practices-acquisition, assimilation, and application of new knowledge-as an effective response mechanism. Our mediation analysis 
confirms that "knowledge acquisition and knowledge assimilation" sequentially mediate the link between supply chain risk and knowledge application (H4-H6).

Furthermore, we find that knowledge application, which encompasses knowledge acquisition and assimilation, is a significant predictor of RMC (H2). We argue that the constant application of knowledge on the negative consequences of risks motivates firms to implement change at each level as an intrinsic part of their day-to-day operations. RMC also establishes a culture of open discussion on potential uncertainties, encourages employees to share their concerns, and maintains processes that help alleviate threats in the future (Rodriguez and Edwards, 2009; Zsidisin et al. 2005b)

Once the desired RMC is established, the next step is to achieve SCRes. Our results support the hypothesis that RMC positively influences SCRes (H3). As such, our research validates the previous conceptualization about organizational culture as a key differentiating factor between successful and unsuccessful firms (Sheffi and Rice, 2005) and establishes RMC as a linking pin between firms' knowledge management practices and their SCRes.

Underpinning DCT, we provide a theoretical standpoint that exposure to risk drives firms to knowledge management practices, which, in turn, enhance RMC leading to SCRes a dynamic capability. We thus contribute to the empirical literature of DCT by explicating how dynamic capabilities are developed in the wake of supply chain risks. While cultivation of RMC has always been found challenging (Christopher and Peck, 2004), our analysis adds to the literature that risk-specific knowledge management practices (knowledge acquisition, assimilation, application) positively and significantly enhance RMC.

SCM literature, in general, and SCRes literature, in particular, is sparse of empirical research on agri-food. Nonetheless, developing resiliency in agri-food supply chain should be at the top of the agenda to maintain an uninterrupted flow of food and reduce the risk of disruption from unexpected disasters such as the current pandemic (Kumar and Kumar Singh, 
2021; Hobbs, 2021). Through the availability of validated measurement items on an emerging topic, this study motivates and attracts more empirical studies, thereby expanding the empirical body of knowledge on both supply risk and SCRes in agri-food supply chain.

\subsection{Practical implications}

The findings of this study present some useful guidelines for practitioners and policymakers who are motivated to develop more resilient Australian agri-food supply chains. First, we suggest that exposure to risks should be considered a forerunner and trigger to improve dynamic capabilities and safeguard performance facing today's turbulent business environment. Prior research shows that contemporary agri-food supply chains are fragmented with little to no knowledge and information sharing culture, making them vulnerable to serious disruptions and sustainability threats (Ali et al., 2017; Glover and Touboulic, 2020). Building upon the data analysis, we draw managers' attention toward the significance of knowledge management practices such as knowledge acquisition, assimilation, and application in a sequential manner. For example, our findings establish that firms facing supply chain risks need to acquire new knowledge by scanning the internal and external environment. To do so, firms should break functional silos and traditional organizational boundaries and thereby organize regular meetings, frequent communication, and resource exchange with key stakeholders. After acquiring new knowledge, the next important step for the firms is to assimilate it; that is, analyze and interpret the knowledge and help employees furnish their knowledge base and skills. Knowledge acquisition and assimilation would not generate benefits without appropriate knowledge application (Rodriguez and Edwards, 2009; Cantor et al., 2014; Cao et al., 2010; Hora and Klassen, 2013; Ambulkar et al., 2015; Massingham, 2010). Here, top management needs to provide employees with resources, autonomy, and responsibility to take decisive actions and solve operational issues using their knowledge. 
Applying knowledge embedded in organizational policies and procedures helps communicate risk management responsibilities and influence behaviors that spur business changes, thereby promoting a positive RMC. The use of available knowledge during recruitment and introduction sessions helps articulate what values and behaviors are expected from a new entity and how risk management is valued and rewarded, which work as a powerful catalyst to implement RMC. Thus, firm managers are advised to acknowledge that the development of RMC as a precursor to SCRes takes time and knowledge management practices that should resonate with people working in the firm, and RMC should be reflected in human resource management policies and employees' work practices.

Further, our analysis suggests that such knowledge-based activities work as a key precursor to creating RMC. To this end, we suggest managers develop formal training and rewards systems to encourage employee involvement and support teamwork and feedback loops. The success of RMC can also be enhanced by extending its implementation to all departments of a firm and the entirety of the supply chain. When knowledge management and RMC are jointly employed, they can help firms promptly sense a threat and integrate, build, and reconfigure resources leading to resilience in the whole supply chain. Finally, while our findings mainly concentrate on agri-food industry; however, we believe that other industries can also learn some key lessons. For instance, from our analysis and key findings, other industries can learn that effective supply chain resilience is achieved when firms in a supply chain follow a structured knowledge management process in response to disruptions or prevalent risks and thereby develop a culture (norms and behavior) of risk management. The findings position knowledge management and RMC as the key linking pins between supply chain risks/disruptions and the firm's goal of supply chain resilience.

\subsection{Limitations and future research avenues}


While this study offers significant contributions, it is not free from the limitations which may provide an impetus for further research. First, the data is collected from a single country and therefore comes with cultural and geographical limitations. As such, we call for empirical research in different agri-food industry/country contexts to gain insights into a diversified set of challenges and resources, and capabilities used to maintain or enhance performance in a rapidly changing business environment. To this end, our framework can be replicated in similar industry sectors by incorporating some contextual modification. Our tested measures and constructs (Table I) offer a great opportunity to extend this study to other industries, for example, hospitality, automotive, construction, ICT, etc. Doing so, the researchers could make minor contextual amendments in measures of proposed constructs, given the industry under investigation. We believe that the extension of our study to other studies will help enrich the literature by gleaning multiple and broader perspectives on the topic. The grey literature and real-world evidence suggest a connection between SCRes, risk, and sustainability; our model could provide premises to devise a framework at the intersection of these three concepts. Expanding upon our model, future research can use operational performance or supply chain sustainably as outcome variables. Future research could also delve deeper into the relationships in this model through qualitative research. Likewise, despite its growing importance and vitality, the agri-food industry may exhibit different characteristics compared to other industries, which may limit the cross-industry generalisability of our research. While the connection between knowledge management practices, risk management, and supply chain resilience permeates different industries, the linkages may be manifested slightly differently in different industries with different boundary conditions. Thus, future research could examine these linkages across various industries with unique boundary conditions.

While multi-method research design offers more rigorous and triangulated results, extant scholarship on supply chain risk and resilience is scant on such research design. Our 
framework provides the foundation to execute multi-method or mixed-method research. Given that supply chain risk and resilience are dynamic entities (Ali et al. 2018; Ponomarov and Holcomb, 2009), a longitudinal study should be conducted to examine the changes in the extent of supply chain risks and resilience over time. The current research is limited to a single respondent from each company. Prospective studies could involve two survey participants from each firm to triangulate the data. Also, conceptual work on a rather unified definition of SCRes is needed, as currently, multiple conceptualizations are being used. Future research can also address the intervening impact of robustness along with the factors mentioned in our study to further explore the connection between knowledge management and SCRes. Future studies can also focus on tacit knowledge and how knowledge and risk management culture is transferable in supply chain management.

Finally, the scenario-based experimental methodology could be employed by research examining SCRes, as it enables researchers to explore circumstances where firms might be unwilling, unable, or uncomfortable to share complete details (Pilling et al., 1994). SCRes is about tackling adversity, problems, and disruptions in supply chains and may involve uncovering sensitive and, at times, controversial issues. Hence, the scenario-based experimental methodology may be a suitable approach to dig deeper into issues that cannot be covered by secondary data or cross-sectional survey research. Likewise, scenarios in such studies allow researchers to manipulate the impact of independent variables, especially when lacking reliable measures, to better establish the potential causality between the independent and dependent variables (Golgeci and Ponomarov, 2013). Thus, we call for further scenariobased experimental studies on SCRes, especially concerning its unexplored antecedents. For example, drawing on experimental research approach, prospective research can explore the interplay among various digital technologies and SCRes in view of the increasing attention on the digitalization of food supply chains (e.g., Ali et al., 2021). 


\section{References}

Aarikka-Stenroos, L. and Jaakkola, E. (2012), "Value co-creation in knowledge intensive business services: A dyadic perspective on the joint problem solving process", Industrial Marketing Management, Vol. 41 No. 1, pp. 15-26.

Aitken, J., Childerhouse, P., Deakins, E. and Towill, D. (2016), “A comparative study of manufacturing and service sector supply chain integration via the uncertainty circle model", The International Journal of Logistics Management, Vol. 27 No. 1, pp. 188-205.

Ali, I., Arslan, A., Khan, Z., \& Tarba, S. Y. (2021), "The Role of Industry 4.0 Technologies in Mitigating Supply Chain Disruption: Empirical Evidence From the Australian Food Processing Industry". IEEE Transactions on Engineering Management, Vol. ahead-of-print No. ahead-ofprint. https://doi.org/10.1109/TEM.2021.3088518

Ali, I. and Gölgeci, I. (2019), "Where is supply chain resilience research heading? A systematic and cooccurrence analysis", International Journal of Physical Distribution \& Logistics Management, Vol. 49 No. 8, pp. 793-815.

Ali, I. and Gölgeci, I. (2020), "Managing climate risks through social capital in agrifood supply chains", Supply Chain Management: An International Journal, Vol. 26 No. 1, pp. 1-16.

Ali, I., \& Govindan, K. (2021), "Extenuating operational risks through digital transformation of agrifood supply chains", Production Planning \& Control, Vol. ahead-of-print No. ahead-of-print. https://doi.org/10.1080/09537287.2021.1988177

Ali, I., Nagalingam, S. and Gurd, B. (2017), "Building resilience in SMEs of perishable product supply chains: enablers, barriers and risks", Production Planning \& Control, Vol. 28 No. 15, pp. 12361250.

Ali, I., Nagalingam, S. and Gurd, B. (2018), "A resilience model for cold chain logistics of perishable products", The International Journal of Logistics Management, Vol. 29 No. 3, pp. 922-941.

Ambulkar, S., Blackhurst, J. and Grawe, S. (2015), "Firm's resilience to supply chain disruptions: Scale development and empirical examination", Journal of Operations Management, Vol. 33 No. 2, pp. 111-122.

Ambulkar, S., Blackhurst, J.V. and Cantor, D.E. (2016), "Supply chain risk mitigation competency: an individual-level knowledge-based perspective", International Journal of Production Research, Vol. 54 No. 5, pp. 1398-1411.

Armstrong, J.S. and Overton, T.S. (1977), "Estimating Nonresponse Bias in Mail Surveys", Journal of Marketing Research, Vol. 14 No. 3, pp. 396-402.

Ates, A. and Bititci, U. (2011), "Change process: a key enabler for building resilient SMEs", International Journal of Production Research, Vol. 49 No. 18, pp. 5601-5618.

Bag, S., Gupta, S., and Wood, L. (2020). "Big data analytics in sustainable humanitarian supply chain: barriers and their interactions", Annals of Operations Research, Vol. ahead-of-print No. aheadof-print. https://doi.org/10.1007/s10479-020-03790-7

Bakshi, N. and Kleindorfer, P. (2007), "Co-Opetition and investment for resilience in global supply chains", Risk Management and Decision Processes Center, The Wharton School of the University of Pennsylvania, USA.

Barbosa, M.W. (2021), "Uncovering research streams on agrifood supply chain management: A bibliometric study", Global Food Security, Vol. 28 No., pp. 100517.

Behzadi, G., O'Sullivan, M.J., Olsen, T.L. and Zhang, A. (2017), "Agribusiness supply chain risk management: a review of quantitative decision models", Omega, Vol. Paper in press No.

Brandon-Jones, E., Squire, B., Autry, C. and Petersen, K.J. (2014), "A Contingent Resource-Based Perspective of Supply Chain Resilience and Robustness", Journal of Supply Chain Management, Vol. 50 No. 3, pp. 55-73.

Cantor, D.E., Blackhurst, J., Pan, M. and Crum, M. (2014), "Examining the role of stakeholder pressure and knowledge management on supply chain risk and demand responsiveness", The International Journal of Logistics Management, Vol. 25 No. 1, pp. 202-223.

Cao, M., Vonderembse, M.A., Zhang, Q. and Ragu-Nathan, T.S. (2010), "Supply chain collaboration", International Journal of Production Research, Vol. 48 No. 21/22, pp. 6613-6635. 
Chaudhuri, A., Ghadge, A., Gaudenzi, B. and Dani, S. (2020), "A conceptual framework for improving effectiveness of risk management in supply networks", The International Journal of Logistics Management, Vol. 31 No. 1, pp. 77-98.

Chen, J., Sohal, A.S. and Prajogo, D.I. (2013), "Supply chain operational risk mitigation: a collaborative approach”, International Journal of Production Research, Vol. 51 No. 7, pp. 2186-2199.

Chowdhury, M.M.H. and Quaddus, M. (2016), "Supply chain readiness, response and recovery for resilience", Supply Chain Management, Vol. 21 No. 6, pp. 709-731.

Christopher, M., Mena, C., Khan, O. and Yurt, O. (2011), "Approaches to managing global sourcing risk", Supply Chain Management: An International Journal, Vol. 16 No. 2, pp. 67-81.

Christopher, M. and Peck, H. (2004), "Building the Resilient Supply Chain", The International Journal of Logistics Management, Vol. 15 No. 2, pp. 1-14.

Churchill, G.A. (1979), “A paradigm for developing better measures of marketing constructs”, Journal of Marketing Research, Vol. 16 No. 1, pp. 64-73.

Colicchia, C. and Strozzi, F. (2012), "Supply chain risk management: a new methodology for a systematic literature review", Supply Chain Management: An International Journal, Vol. 17 No. 4, pp. 403-418.

Craighead, C.W., Ketchen, D.J., Dunn, K.S. and Hult, G.T.M. (2011), “Addressing common method variance: guidelines for survey research on information technology, operations, and supply chain management", IEEE transactions on engineering management, Vol. 58 No. 3, pp. 578588.

Darroch, J. (2003), "Developing a measure of knowledge management behaviors and practices", Journal of knowledge management, Vol. 7 No. 5, pp. 41-54.

Do, H., Budhwar, P.S. and Patel, C. (2018), "Relationship between innovation-led HR policy, strategy, and firm performance: A serial mediation investigation", Human Resource Management, Vol. 57 No. 5, pp. 1271-1284.

Donaldson, L. (2001) The contingency theory of organizations. London, UK: Sage publications.

Drazin, R. and Van De Ven, A.H. (1985), "Alternative Forms of Fit in Contingency Theory", Administrative Science Quarterly, Vol. 30 No. 4, pp. 514-539.

Dubey, R., Gunasekaran, A., Childe, S.J., Fosso Wamba, S., Roubaud, D. and Foropon, C. (2019), "Empirical investigation of data analytics capability and organizational flexibility as complements to supply chain resilience", International Journal of Production Research, Vol. ahead-of-print No. ahead-of-print.

Dubey, R., Gunasekaran, A., Childe, S.J., Papadopoulos, T., Blome, C. and Luo, Z. (2017), "Antecedents of Resilient Supply Chains: An Empirical Study", IEEE Transactions on Engineering Management, Vol. 66 No. 1, pp. 8-19.

Enkel, E., Heil, S., Hengstler, M. and Wirth, H. (2017), "Exploratory and exploitative innovation: To what extent do the dimensions of individual level absorptive capacity contribute?", Technovation, Vol. 60-61 No., pp. 29-38.

Ferraris, A., Santoro, G. and Dezi, L. (2017), "How MNC's subsidiaries may improve their innovative performance? The role of external sources and knowledge management capabilities", Journal of Knowledge Management, Vol. 21 No. 3, pp. 540-552.

Fornell, C. and Larcker, D.F. (1981), "Evaluating structural equation models with unobservable variables and measurement error", Journal of marketing research, Vol. 18 No. 1, pp. 39-50.

Glover, J. and Touboulic, A. (2020), "Tales from the countryside: Unpacking "passing the environmental buck" as hypocritical practice in the food supply chain", Journal of Business Research, Vol. 121 No., pp. 33-46.

Gölgeci, I. and Kuivalainen, O. (2020), "Does social capital matter for supply chain resilience? The role of absorptive capacity and marketing-supply chain management alignment", Industrial Marketing Management, Vol. 84 No., pp. 63-74.

Golgeci, I. and Ponomarov, S.Y. (2013), "Does firm innovativeness enable effective responses to supply chain disruptions? An empirical study", Supply Chain Management: An International Journal, Vol. 18 No. 6, pp. 604-617.

Golgeci, I., Yildiz, H.E. and Andersson, U.R. (2020), "The rising tensions between efficiency and resilience in global value chains in the post-COVID-19 world", Transnational Corporations Journal, Vol. 27 No. 2. 
Grant, R.M. (1996), "Toward a knowledge-based theory of the firm", Strategic management journal, Vol. 17 No. S2, pp. 109-122.

Hair, J.F., Anderson, R.E., Babin, B.J. and Black, W.C. 2010. Multivariate data analysis: A global perspective. Úpper Saddle River, NJ: Pearson.

Handfield, R., Sun, H. and Rothenberg, L. (2020), "Assessing supply chain risk for apparel production in low cost countries using newsfeed analysis", Supply Chain Management: An International Journal, Vol. 25 No. 6, pp. 803-821.

Harman, H.H. (1976) Modern factor analysis. Chicago, USA: University of Chicago Press.

Ho, W., Zheng, T., Yildiz, H. and Talluri, S. (2015), "Supply chain risk management: a literature review", International Journal of Production Research, Vol. 53 No. 16, pp. 5031-5069.

Hobbs, J.E. (2021), "Food supply chains during the COVID-19 pandemic", Canadian Journal of Agricultural Economics, Vol. 68 No. 2, pp. 171-176.

Hoffer, C.W. (1975), "Toward a Contingency Theory of Business Strategy", Academy of Management Journal, Vol. 18 No. 4, pp. 784-810.

Hora, M. and Klassen, R.D. (2013), "Learning from others' misfortune: Factors influencing knowledge acquisition to reduce operational risk", Journal of Operations Management, Vol. 31 No. 1, pp. 52-61.

Hu, L.T. and Bentler, P.M. (1999), "Cutoff criteria for fit indexes in covariance structure analysis: Conventional criteria versus new alternatives", Structural Equation Modeling: A Multidisciplinary Journal, Vol. 6 No. 1, pp. 1-55.

Huertas-Valdivia, I., Llorens-Montes, F.J. and Ruiz-Moreno, A. (2018), "Achieving engagement among hospitality employees: A serial mediation model", International Journal of Contemporary Hospitality Management, Vol. 30 No. 1, pp. 217-241.

Hult, G.T.M., Craighead, C.W. and Ketchen Jr, D.J. (2010), "Risk Uncertainty and Supply Chain Decisions: A Real Options Perspective”, Decision Sciences, Vol. 41 No. 3, pp. 435-458.

Hult, G.T.M., Ketchen, D.J. and Arrfelt, M. (2007), "Strategic supply chain management: Improving performance through a culture of competitiveness and knowledge development", Strategic Management Journal, Vol. 28 No. 10, pp. 1035-1052.

Jain, V., Kumar, S., Soni, U. and Chandra, C. (2017), "Supply chain resilience: model development and empirical analysis", International Journal of Production Research, Vol. 55 No. 22, pp. 67796800.

Jansen, J.J.P., Van Den Bosch, F.A.J. and Volberda, H.W. (2005), "Managing potential and realized absorptive capacity: How do organizational antecedents matter?", Academy of Management Journal, Vol. 48 No. 6, pp. 999-1015.

Juan Ding, M., Jie, F., A. Parton, K. and J. Matanda, M. (2014), "Relationships between quality of information sharing and supply chain food quality in the Australian beef processing industry", The International Journal of Logistics Management, Vol. 25 No. 1, pp. 85-108.

Jüttner, U., Peck, H. and Christopher, M. (2003), "Supply chain risk management: outlining an agenda for future research", International Journal of Logistics Research and Applications, Vol. 6 No. 4, pp. 197-210.

Kaufman, A., Wood, C.H. and Theyel, G. (2000), "Collaboration and technology linkages: a strategic supplier typology", Strategic Management Journal, Vol. 21 No. 6, pp. 649-663.

Kleindorfer, P.R. and Saad, G.H. (2005), "Managing Disruption Risks in Supply Chains", Production and Operations Management, Vol. 14 No. 1, pp. 53-68.

Kumar, A., Garg, R.K. and Garg, D. (2019), "An empirical study to identify and develop constructive model of e-supply chain risks based on Indian mechanical manufacturing industries", Management Science Letters, Vol. 9 No. 2, pp. 217-228.

Kumar, P. and Kumar Singh, R. (2021), "Strategic framework for developing resilience in Agri-Food Supply Chains during COVID 19 pandemic", International Journal of Logistics Research and Applications, Vol. No., pp. 1-24.

Kumar, S. and Anbanandam, R. (2020), "Impact of risk management culture on supply chain resilience: An empirical study from Indian manufacturing industry", Proceedings of the Institution of Mechanical Engineers, Part O: Journal of Risk and Reliability, Vol. 234 No. 2, pp. 246-259.

Kumar, V., Bak, O., Guo, R., Shaw, S.L., Colicchia, C., Garza-Reyes, J.A. and Kumari, A. (2018), “An empirical analysis of supply and manufacturing risk and business performance: A Chinese 
manufacturing supply chain perspective", Supply Chain Management: An International Journal, Vol. 23 No. 6, 461-479

Leat, P. and Revoredo-Giha, C. (2013), "Risk and resilience in agrifood supply chains: the case of the ASDA PorkLink supply chain in Scotland", Supply Chain Management: An International Journal, Vol. 18 No. 2, pp. 219-231.

Li, S., Ragu-Nathan, B., Ragu-Nathan, T.S. and Subba Rao, S. (2006), "The impact of supply chain management practices on competitive advantage and organizational performance", Omega, Vol. 34 No. 2, pp. 107-124.

Liu, C.L., Shang, K.C., Lirn, T.C., Lai, K.H. and Lun, Y.H.V. (2018), "Supply chain resilience, firm performance, and management policies in the liner shipping industry", Transportation Research Part A: Policy and Practice, Vol. 110 No., pp. 202-219.

López, C. and Ishizaka, A. (2019), "A hybrid FCM-AHP approach to predict impacts of offshore outsourcing location decisions on supply chain resilience", Journal of Business Research, Vol. 103 No., pp. 495-507.

Madow, W.G. (1953), "On the theory of systematic sampling, III. Comparison of centered and random start systematic sampling", The Annals of Mathematical Statistics, Vol. No., pp. 101-106.

Manuj, I. and Mentzer, J.T. (2008a), "Global supply chain risk management", Journal of Business Logistics, Vol. 29 No. 1, pp. 133-155.

Manuj, I. and Mentzer, J.T. (2008b), "Global supply chain risk management strategies", International Journal of Physical Distribution \& Logistics Management, Vol. 38 No. 3, pp. 192-223.

Mason-Jones, R. and Towill, D.R. (1998), "Shrinking the supply chain uncertainty circle", The Institute of Operations Management Control Journal Vol. 24 No. 7, pp. 17-22.

Massingham, P. (2010), "Knowledge risk management: a framework", Journal of Knowledge Management, Vol. 14 No. 3, pp. 464-485.

McEvily, S.K. and Chakravarthy, B. (2002), "The persistence of knowledge-based advantage: an empirical test for product performance and technological knowledge", Strategic Management Journal, Vol. 23 No. 4, pp. 285-305.

Mentzer, J.T. and Flint, D.J. (1997), "Validity in logistics research", Journal of Business Logistics, Vol. 18 No. 1, pp. 199.

Moazzam, M., Akhtar, P., Garnevska, E. and Marr, N.E. (2018), "Measuring agrifood supply chain performance and risk through a new analytical framework: a case study of New Zealand dairy", Production Planning \& Control, Vol. 29 No. 15, pp. 1258-1274.

Nunnally, J.C. 1978. Psychometric Theory New York: McGraw-Hill.

Pettit, T.J., Croxton, K.L. and Fiksel, J. (2013), "Ensuring Supply Chain Resilience: Development and Implementation of an Assessment Tool", Journal of Business Logistics, Vol. 34 No. 1, pp. 4676.

Pilling, B.K., Crosby, L.A. and Jackson, D.W. (1994), "Relational bonds in industrial exchange: an experimental test of the transaction cost economic framework", Journal of Business Research, Vol. 30 No. 3, pp. 237-251.

Pitelis, C.N. and Teece, D.J. (2010), "Cross-border market co-creation, dynamic capabilities and the entrepreneurial theory of the multinational enterprise", Industrial and Corporate Change, Vol. 19 No. 4, pp. 1247-1270.

Ponomarov, S.Y. (2012) Antecedents and Consequences of Supply Chain Resilience: A Dynamic Capabilities Perspective. PhD in Business Administration Dissertation The University of Tennessee, Knoxville, TN.

Ponomarov, S.Y. and Holcomb, M.C. (2009), "Understanding the concept of supply chain resilience", The International Journal of Logistics Management, Vol. 20 No. 1, pp. 124-143.

Rao, S. and Goldsby, T.J. (2009), "Supply chain risks: a review and typology", International Journal of Logistics Management, Vol. 20 No. 1, pp. 97-123.

Revilla, E., Revilla, E., Saenz, M.J. and Saenz, M.J. (2017), "The impact of risk management on the frequency of supply chain disruptions: A configurational approach", International Journal of Operations \& Production Management, Vol. 37 No. 5, pp. 557-576.

Ritchie, B. and Brindley, C. (2007), "Supply chain risk management and performance: A guiding framework for future development", International Journal of Operations \& Production Management, Vol. 27 No. 3, pp. 303-322. 
Rodriguez, E. and Edwards, J.S. (2009) "Knowledge management and enterprise risk management implementation in financial services". Proceedings of 2009 Enterprise Risk Management Symposium, Chicago, Il.

Roeschmann, A.Z. (2014), "Risk culture: What it is and how it affects an insurer's risk management", Risk Management and Insurance Review, Vol. 17 No. 2, pp. 277-296.

Sande, J.B. and Ghosh, M. (2018), "Endogeneity in survey research", International Journal of Research in Marketing, Vol. 35 No. 2, pp. 185-204.

Schilke, O., Hu, S. and Helfat, C.E. (2018), "Quo vadis, dynamic capabilities? A content-analytic review of the current state of knowledge and recommendations for future research", Academy of Management Annals, Vol. 12 No. 1, pp. 390-439.

Scholten, K., Scott, P. and Fynes, B. (2014), "Mitigation processes-antecedents for building supply chain resilience", Supply Chain Management: An International Journal, Vol. 19 No. 2, pp. 88.

Schweiger, S.A., Stettler, T.R., Baldauf, A. and Zamudio, C. (2019), "The complementarity of strategic orientations: A meta-analytic synthesis and theory extension", Strategic Management Journal, Vol. 40 No. 11, pp. 1822-1851.

Sheffi, Y. and Rice, J.B. (2005), "A supply chain view of the resilient enterprise", MIT Sloan Management Review, Vol. 47 No. 1, pp. 41-48.

Siddh, M.M., Soni, G., Jain, R., Sharma, M.K. and Yadav, V. (2017), "Agri-fresh food supply chain quality (AFSCQ): a literature review”, Industrial Management \& Data Systems, Vol. 117 No. 9, pp. 2015-2044.

Talluri, S.S., Kull, T.J., Yildiz, H. and Yoon, J. (2013), "Assessing the Efficiency of Risk Mitigation Strategies in Supply Chains", Journal of Business Logistics, Vol. 34 No. 4, pp. 253-269.

Teece, D.J. (2007), "Explicating dynamic capabilities: The nature and microfoundations of (sustainable) enterprise performance", Strategic Management Journal, Vol. 28 No. 13, pp. 1319-1350.

Teece, D.J. (2014), "A dynamic capabilities-based entrepreneurial theory of the multinational enterprise", Journal of International Business Studies, Vol. 45 No. 1, pp. 8-37.

Teece, D.J., Pisano, G. and Shuen, A. (1997), "Dynamic capabilities and strategic management", Strategic Management Journal, Vol. 18 No. 7, pp. 509-533.

Teller, J. and Kock, A. (2013), "An empirical investigation on how portfolio risk management influences project portfolio success", International Journal of Project Management, Vol. 31 No. 6, pp. 817-829.

Tse, Y.K., Zhang, M., Tan, K.H., Pawar, K. and Fernandes, K. (2019), "Managing quality risk in supply chain to drive firm's performance: The roles of control mechanisms", Journal of Business Research, Vol. 97 No., pp. 291-303.

Tse, Y.K., Zhang, M., Zeng, W. and Ma, J. (2021), "Perception of supply chain quality risk: Understanding the moderation role of supply market thinness", Journal of Business Research, Vol. 122 No., pp. 822-834.

Umar, M., Wilson, M. and Heyl, J. (2017), "Food network resilience against natural disasters: a conceptual framework", Sage open, Vol. 7 No. 3, pp. 2158244017717570.

USDA (2021) Ag and Food Sectors and the Economy: USDA. Available at: https://www.ers.usda.gov/data-products/ag-and-food-statistics-charting-the-essentials/ag-andfood-sectors-and-the-economy/ (Accessed: 16 September 2021).

Wagner, S.M. and Bode, C. (2006), "An empirical investigation into supply chain vulnerability", Journal of Purchasing and Supply Management, Vol. 12 No. 6, pp. 301-312.

Wagner, S.M. and Bode, C. (2008), "An empirical examination of supply chain performance along several dimensions of risk", Journal of Business Logistics, Vol. 29 No. 1, pp. 307-325.

Wang, E., Klein, G. and Jiang, J.J. (2007), "IT support in manufacturing firms for a knowledge management dynamic capability link to performance", International Journal of Production Research, Vol. 45 No. 11, pp. 2419-2434.

Wang, X., Tiwari, P. and Chen, X. (2017), "Communicating supply chain risks and mitigation strategies: a comprehensive framework", Production Planning \& Control, Vol. 28 No. 13, pp. 1023-1036. 
Williams, L. J., Hartman, N. and Cavazotte, F. (2010), "Method variance and marker variables: A review and comprehensive CFA marker technique", Organizational research methods, Vol. 13 No. 3, pp. 477-514.

World Bank (2021) Agriculture, Forestry, Fishing Value added (\% of GDP). Available at: https://data.worldbank.org/indicator/NV.AGR.TOTL.ZS (Accessed: 20 September 2021).

Xie, X., Zou, H. and Qi, G. (2018), "Knowledge absorptive capacity and innovation performance in high-tech companies: A multi-mediating analysis", Journal of Business Research, Vol. 88 No., pp. 289-297.

Yeniyurt, S., Cavusgil, S.T. and Hult, G.T.M. (2005), "A global market advantage framework: the role of global market knowledge competencies", International Business Review, Vol. 14 No. 1, pp. $1-19$.

Zahra, S.A. and George, G. (2002), "Absorptive capacity: A review, reconceptualization, and extension", Academy of Management Review, Vol. 27 No. 2, pp. 185-203.

Zhang, M., Zhao, X., Lyles, M.A. and Guo, H. (2015), "Absorptive capacity and mass customization capability", International Journal of Operations and Production Management, Vol. 35 No. 9 , pp. 1275-1294.

Zhao, X., Wang, P. and Pal, R. (2021), "The effects of agro-food supply chain integration on product quality and financial performance: Evidence from Chinese agro-food processing business", International Journal of Production Economics, Vol. 231 No. 1, pp. 107832.

Zhong, R., Xu, X. and Wang, L. (2017), "Food supply chain management: systems, implementations, and future research", Industrial Management \& Data Systems, Vol. 117 No. 9, pp. 2085-2114.

Zsidisin, G.A. (2003), "Managerial Perceptions of Supply Risk", Journal of Supply Chain Management, Vol. 39 No. 1, pp. 14-26.

Zsidisin, G. A., Ellram, L. M., Carter, J. R. and Cavinato, J. L. (2004) 'An analysis of supply risk assessment techniques', International Journal of Physical Distribution \& Logistics Management, Vol. 34, No. 5, pp. 397-413.

Zsidisin, G.A., Melnyk, S.A. and Ragatz, G.L. (2005a), "An institutional theory perspective of business continuity planning for purchasing and supply management", International Journal of Production Research, Vol. 43 No. 16, pp. 3401-3420.

Zsidisin, G.A., Panelli, A. and Upton, R. (2000), "Purchasing organization involvement in risk assessments, contingency plans, and risk management: an exploratory study", Supply Chain Management: An International Journal, Vol. 5 No. 4, pp. 187-198.

Zsidisin, G. A., Ragatz, G. L. and Melnyk, S. A. (2005b), "The dark side of supply chain management", Supply Chain Management Review, Vol. 9 No. 2, pp. 46-52.

Zsidisin, G. A. and Wagner, S. M. (2010), "Do perceptions become reality? The moderating role of supply chain resiliency on disruption occurrence", Journal of business logistics, Vol. 31 No. 2 , pp. 1-20. 


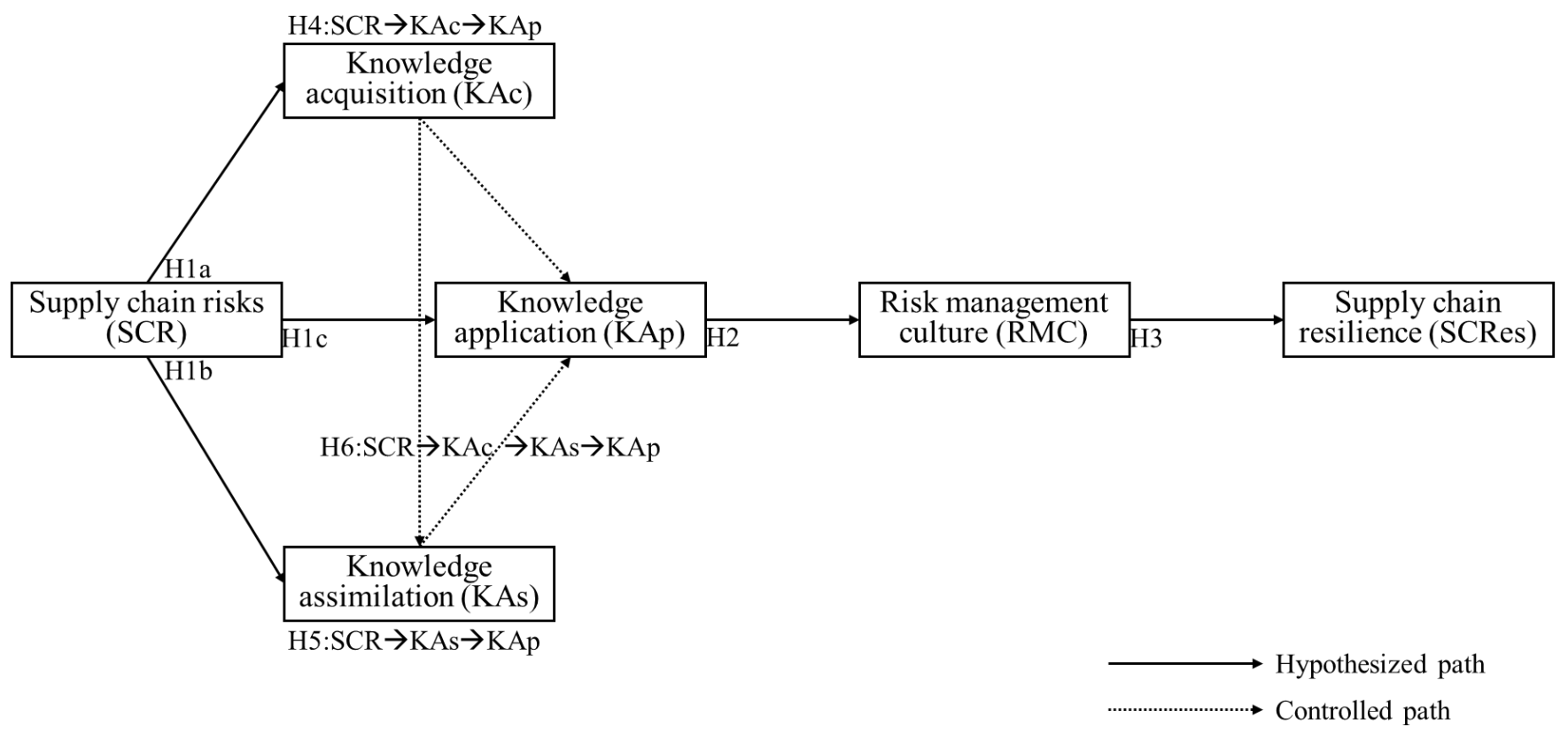

Figure 1. Conceptual model

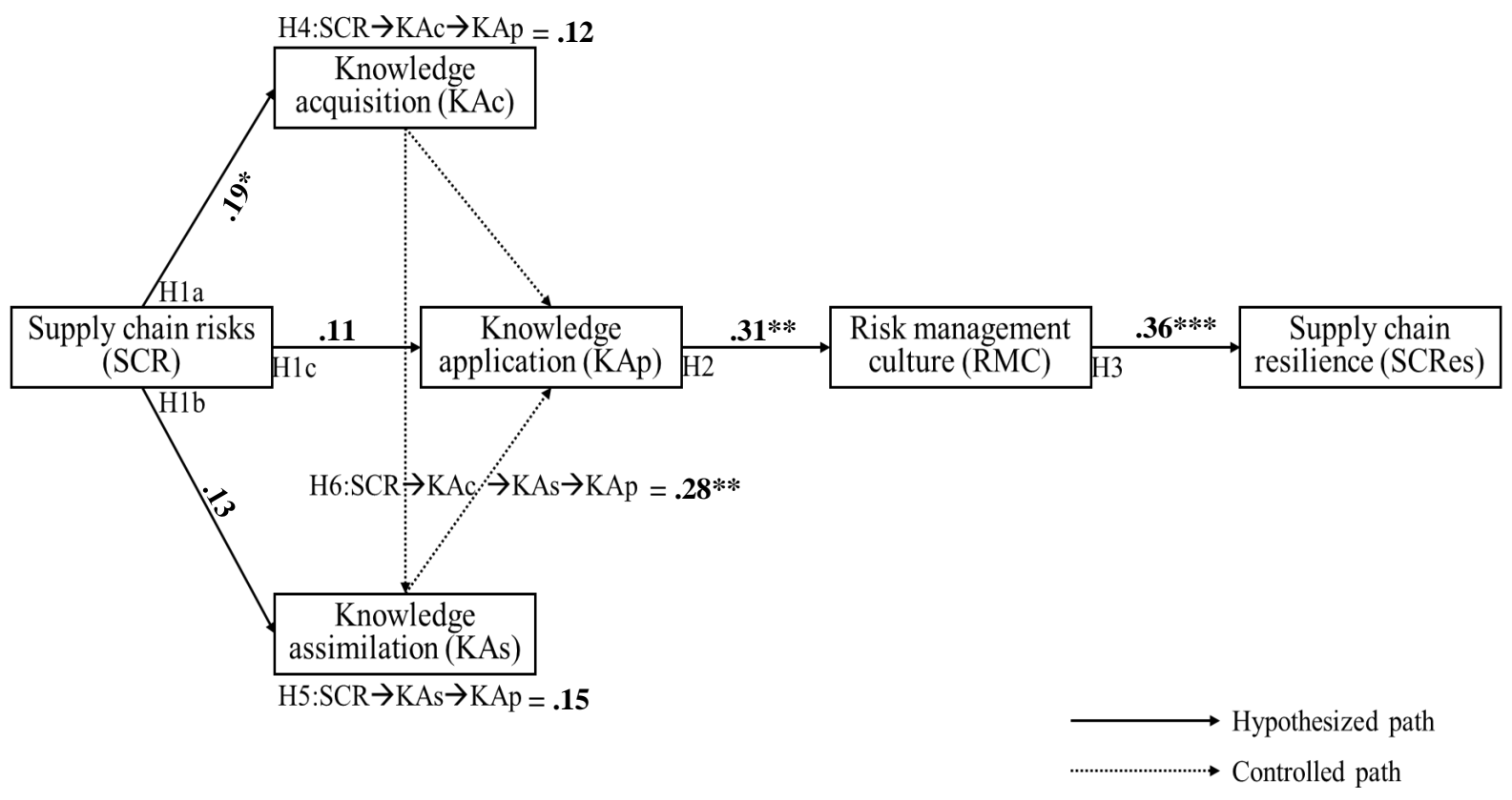

Figure 2. Estimated results of the conceptual model. 
Table I. Construct and item reliability

\begin{tabular}{|c|c|c|c|c|}
\hline Construct & Item & $\begin{array}{l}\text { Factor } \\
\text { loading }\end{array}$ & AVE & $\mathbf{C R}$ \\
\hline \multirow{4}{*}{$\begin{array}{l}\text { Supply Risks } \\
\quad \text { (SR) }\end{array}$} & SR1: Our suppliers inconsistently meet the quality of supplies. & 0.84 & & \\
\hline & SR2: Our suppliers inconsistently meet the quantity of supplies. & 0.86 & 0.74 & 0.89 \\
\hline & SR3: Over the past three years, we have lost some key suppliers. & 0.88 & & \\
\hline & SR4: Our suppliers have poor logistics performance (delivery dependability). & 0.87 & & \\
\hline Production & PR1: Our firm often has a shortage of skilled workforce & 0.82 & 0.65 & 0.83 \\
\hline \multirow[t]{3}{*}{ Risks (PR) } & PR2: Our firm faces a high variability in production quality. & 0.79 & & \\
\hline & PR3: Our firm faces a high variability in production quantity. & 0.85 & & \\
\hline & PR4: Our firm faces a high variability in production time. & 0.77 & & \\
\hline \multirow{3}{*}{$\begin{array}{l}\text { Demand Risks } \\
\quad \text { (DR) }\end{array}$} & DR1: Our firm faces drastic changes in the demand pattern. & 0.81 & 0.71 & 0.84 \\
\hline & DR2: Our firm faces insufficient or distorted information from customers. & 0.89 & & \\
\hline & DR3: Our firm faces a lack of coordinated planning with buyers. & 0.83 & & \\
\hline \multirow{7}{*}{$\begin{array}{l}\text { Supply chain } \\
\text { risk (SCR) - } \\
\text { second-order } \\
\text { Knowledge } \\
\text { Acquisition } \\
\text { (KAc) }\end{array}$} & SR: Supply risks & 0.88 & 0.69 & 0.93 \\
\hline & PR: Production risks & 0.81 & & \\
\hline & DR: Demand risk & 0.79 & & \\
\hline & KAc1: Our firm consistently gains supply chain partners' operational information in real-time. & 0.74 & 0.63 & 0.81 \\
\hline & $\begin{array}{l}\text { KAc2: We regularly attend lectures, seminars, and exhibitions to pursue the latest technological } \\
\text { developments and market dynamics. }\end{array}$ & 0.93 & & \\
\hline & $\begin{array}{l}\text { KAc3: Our firm continually organizes special meetings with supply chain partners to deal with } \\
\text { products' supply and demand issues. }\end{array}$ & 0.73 & & \\
\hline & $\begin{array}{l}\text { KAc4: Our firm has formal routines and standard operating procedures to guide regular } \\
\text { managers' interactions with suppliers and buyers. }\end{array}$ & 0.76 & & \\
\hline \multirow{4}{*}{$\begin{array}{l}\text { Assimilation } \\
\text { (KAs) }\end{array}$} & KAs1: Our firm quickly analyzes and interprets newly acquired knowledge. & 0.71 & 0.56 & 0.74 \\
\hline & $\begin{array}{l}\text { KAs2: Our firm regularly organize special training programs that help employees grasp new } \\
\text { knowledge }\end{array}$ & 0.91 & & \\
\hline & $\begin{array}{l}\text { KAs3: We strongly endeavor to assess the potential value of external knowledge with respect to } \\
\text { our business requirements. }\end{array}$ & 0.67 & & \\
\hline & KAs4: Our firm provides incentives to employees who acquire new knowledge. & 0.68 & & \\
\hline \multirow{3}{*}{$\begin{array}{c}\text { Knowledge } \\
\text { application } \\
\text { (KAp) }\end{array}$} & $\begin{array}{l}\text { KAp1: Our firm consistently utilizes new knowledge to solve operational problems and create } \\
\text { new competencies and routines. }\end{array}$ & 0.78 & 0.62 & 0.80 \\
\hline & KAp2: Our firm constantly improves processes given the new knowledge. & 0.69 & & \\
\hline & $\begin{array}{l}\text { KAp3: Our firm effectively and efficiently deploys existing resources in the company to utilize } \\
\text { new knowledge and deal with potential risks. }\end{array}$ & 0.75 & & \\
\hline
\end{tabular}




\begin{tabular}{|c|c|c|c|c|}
\hline Construct & Item & $\begin{array}{l}\text { Factor } \\
\text { loading }\end{array}$ & AVE & $\mathbf{C R}$ \\
\hline & $\begin{array}{l}\text { KAp4: We regularly involve supply chain partners and their complementary capabilities in the } \\
\text { utilization of new knowledge. }\end{array}$ & 0.92 & & \\
\hline $\begin{array}{c}\text { Risk } \\
\text { management }\end{array}$ & $\begin{array}{l}\text { RMC1: Our firm motivates and reward employees to manage risks by utilizing current knowledge } \\
\text { and skills. }\end{array}$ & 0.61 & 0.58 & 0.77 \\
\hline \multirow[t]{3}{*}{ culture (RMC) } & $\begin{array}{l}\text { RMC2: Our firm has included the subject of risk management as an important topic in new } \\
\text { personnel training. }\end{array}$ & 0.94 & & \\
\hline & $\begin{array}{l}\text { RMC3: In collaboration with supply chain partners, we are working on a transparent } \\
\text { communication and open exchange of knowledge on potential threats and their management. }\end{array}$ & 0.72 & & \\
\hline & RMC4: Risk awareness is intrinsic part of our business operations. & 0.76 & & \\
\hline $\begin{array}{l}\text { Supply chain } \\
\text { resilience }\end{array}$ & $\begin{array}{l}\text { SCRes1: Our firm proactively updates people, processes, and systems in line with the changes in } \\
\text { the external business environment. }\end{array}$ & 0.95 & 0.81 & 0.92 \\
\hline \multirow[t]{3}{*}{ (SCRes) } & $\begin{array}{l}\text { SCRes2: Our firm possess capabilities and resources to effectively react and adapt to the } \\
\text { unexpected risks }\end{array}$ & 0.98 & & \\
\hline & SCRes2: Our firm uses multiple sources of suppliers and buyers. & 0.96 & & \\
\hline & $\begin{array}{l}\text { SCRes4: Our firm possesses the capabilities and resources to absorb unexpected disruptions and } \\
\text { fast to recover from disruptions. }\end{array}$ & 0.68 & & \\
\hline
\end{tabular}


Table II. Discriminant validity.

\begin{tabular}{cccccccccc}
\hline Construct & SR & PR & DR & SCR & KCc & KAs & KAp & RMC & SCRes \\
\hline SR & $\mathbf{0 . 8 6}$ & & & & & & & & \\
PR & 0.56 & $\mathbf{0 . 8 1}$ & & & & & & & \\
DR & 0.77 & 0.67 & $\mathbf{0 . 8 4}$ & & & & & & \\
SCR & 0.78 & 0.75 & 0.55 & $\mathbf{0 . 8 3}$ & & & & & \\
KAc & 0.51 & 0.52 & 0.76 & 0.72 & $\mathbf{0 . 7 9}$ & & & & \\
KAs & 0.54 & 0.58 & 0.79 & 0.59 & 0.63 & $\mathbf{0 . 7 5}$ & & & \\
KAp & 0.53 & 0.59 & 0.73 & 0.65 & 0.57 & 0.69 & $\mathbf{0 . 7 9}$ & & \\
RMC & 0.61 & 0.63 & 0.65 & 0.63 & 0.61 & 0.58 & 0.65 & $\mathbf{0 . 7 6}$ & \\
SCRes & 0.62 & 0.69 & 0.64 & 0.68 & 0.67 & 0.55 & 0.57 & 0.67 & $\mathbf{0 . 9 1}$ \\
\hline AVE
\end{tabular}

$A V E=$ diagonal

Table III. Hypothesis and structural model's statistics.

\begin{tabular}{|c|c|c|c|}
\hline Hypothesized relationship & Path coefficient & $\begin{array}{l}p- \\
\text { value }\end{array}$ & Result \\
\hline \multicolumn{4}{|l|}{ Direct effect } \\
\hline $\begin{array}{l}\text { H1a: A higher exposure to supply chain risks is } \\
\text { positively associated with a firm's knowledge } \\
\text { acquisition. }\end{array}$ & $.19 *$ & 0.031 & Supported \\
\hline $\begin{array}{l}\text { H1b: A higher exposure to supply chain risks is } \\
\text { positively associated with a firm's knowledge } \\
\text { assimilation. }\end{array}$ & .13 & 0.071 & Not supported \\
\hline $\begin{array}{l}\text { H1c: A higher exposure to supply chain risks is } \\
\text { positively associated with a firm's knowledge } \\
\text { application. }\end{array}$ & .11 & 0.087 & Not supported \\
\hline $\begin{array}{l}\text { H2: Knowledge application is positively } \\
\text { associated with firm risk management culture }\end{array}$ & $.31 * *$ & 0.003 & supported \\
\hline $\begin{array}{l}\text { H3: Risk management culture is positively } \\
\text { associated with firm supply chain resilience. }\end{array}$ & $.36 * * *$ & 0.000 & supported \\
\hline \multicolumn{4}{|l|}{ Mediating (indirect) effect } \\
\hline $\begin{array}{l}\text { H4: Exposure to supply chain risk significantly } \\
\text { affects a firm knowledge application through } \\
\text { knowledge acquisition. }\end{array}$ & .12 & 0.082 & Not supported \\
\hline $\begin{array}{l}\text { H5: Exposure to supply chain risk significantly } \\
\text { affects a firm knowledge application through } \\
\text { knowledge assimilation. }\end{array}$ & .15 & 0.067 & Not supported \\
\hline $\begin{array}{l}\text { H6: Exposure to supply chain risk significantly } \\
\text { affects a firm knowledge application through } \\
\text { knowledge acquisition and knowledge } \\
\text { assimilation together (one after another). }\end{array}$ & $.28^{* *}$ & 0.005 & supported \\
\hline
\end{tabular}

